US Army Corps

of Engineers $S_{\circledast}$

Engineer Research and

Development Center

\title{
Vehicle Mobility on Highly Organic Soils
}

Michael Parker, Alexander Stott, Mark Bodie, Susan Frankenstein,

August 2020

and Sally Shoop 
The U.S. Army Engineer Research and Development Center (ERDC) solves the nation's toughest engineering and environmental challenges. ERDC develops innovative solutions in civil and military engineering, geospatial sciences, water resources, and environmental sciences for the Army, the Department of Defense, civilian agencies, and our nation's public good. Find out more at www.erdc.usace.army.mil.

To search for other technical reports published by ERDC, visit the ERDC online library at https://erdclibrary.on.worldcat.org/discovery. 


\section{Vehicle Mobility on Highly Organic Soils}

Michael Parker, Alexander Stott, Mark Bodie, Susan Frankenstein, and Sally Shoop

Cold Regions Research Laboratory

U.S. Army Engineer Research and Development Center

72 Lyme Road

Hanover, NH 03755

Final report

Approved for public release; distribution is unlimited.

Prepared for Assistant Secretary for Army Acquisitions, Logistics \& Technology Washington, DC 20314

Under Program Element 62784, Project AT40, Task Number 48, "Remote assessment of Snow Mechanical Properties" and "Mobility in Peat and Northern Soils" 


\section{Preface}

This study was conducted for the Assistant Secretary of the Army, Acquisition, Logistics and Technology under Program Element 62784, Project Number AT40, and Task Number 48. The technical monitor was John Rushing.

The work was performed by the Terrestrial and Cryospheric Sciences Branch and by the Force Projection and Sustainment Branch of the Research and Engineering Division, U.S. Army Engineer Research and Development Center, Cold Regions Research and Engineering Laboratory (ERDC-CRREL).

At the time of publication, Dr. John Weatherly was Chief, Terrestrial and Cryospheric Sciences Branch; Mr. Justin Putnam was Acting Chief, Force Projection and Sustainment Branch; Mr. Jimmy Horne was Division Chief and Dr. Bert Davis, was the Technical Director for Geospatial Research and Engineering/Military Engineering. The Deputy Director of ERDCCRREL was Mr. David B. Ringelberg, and the Director was Dr. Joseph L. Corriveau.

This paper was originally published as a proceeding of the ISTVS 15th European-African Regional Conference, Prague, Czech Republic, September 9-11, 2019 and funded under the Entry and Sustainment in Complex Contested Environments Project (Mobility in Peat and Northern Soils project under the 6.2 T40 ASTMIS).

The Commander of ERDC was COL Teresa A. Schlosser and the Director was Dr. David W. Pittman. 


\title{
Vehicle Mobility on Highly Organic Soils
}

\begin{abstract}
Current political climates have generated a renewed interest in the northern regions of the world. These areas are known to have soft marshy peat, highly organic soils, and cold harsh winter climates. Currently vehicle mobility modeling capability on this terrain is limited and existing studies do not include current military vehicles. This work presents mobility experiments of current military vehicles at multiple field sites containing peat or highly organic soils that can eventually be used to improve mobility modeling on these soils. Field work is being conducted during multiple seasons including winter, spring, and summer. The vehicle traction, motion resistance, and hard surface rolling resistance of an instrumented High Mobility Multipurpose Wheeled Vehicle (HMMWV) and a Small Unit Support Vehicle (SUSV) were examined. The first is a common multi-purpose vehicle and the second is a vehicle designed to operate in these types of environments. Preliminary analysis of the field test results will be discussed in this paper.
\end{abstract}

\section{Introduction}

The physical behavior of peat and highly organic soils is not well known because they are not used for engineering or maneuver corridors as they are typically saturated with water, soft, and unstable to build on. Much of the global northern terrain contains large amounts of peat/organic soil in areas that are important to maneuver and sustainment operations such as agricultural fields, peat farms, and nearby forest. This work is focused on understanding mobility relationships for current military vehicles operating on highly organic soil that can later be used to generate mobility predictors for other vehicles maneuvering in these environs as they dominate northern boreal and sub-boreal environments such as Scandinavia, the Baltic States, and Korea.

Currently, strength algorithms for peat are non-existent. Mobility prediction codes use a low strength value for unfrozen peat so that the modeled mobility is severely restricted or no-go as expected. This may not always be the case as specially designed vehicles with low ground pressure may traverse the weak organic soils without issue, some organic areas may be drier than others allowing for increased mobility. Frozen organic soils have a significant increase in strength allowing mobility in these areas. This increase in strength and the understanding of how and when peat/organic soils freeze is not well understood or included in current vehicle mobility models which may cause them to under predict vehicle mobility in these areas.

Testing on natural peatlands is severely limited due to environmental regulations and extreme sensitivity of the terrain to any kind of disturbance. Natural peatland surfaces are highly irregular, saturated, often hummocked, and vegetated making vehicle testing nearly impossible except during winter conditions. Previous studies by Shoop et al. (2015) show the impacts of vegetation on vehicle mobility. Wong et al. (1984) focused on creating pressure-sinkage, shearing characteristics, and repetitive loading relationships using a bevameter on muskeg. There are very few of these devices and until recently few, if any, were being used to characterize soil in the field for mobility testing. Bevemeters are complex 
and not very field portable. As a result, there aren't many mobility models that consider these parameters. The Wong et al. (1984) study uses an older tracked vehicle with a different track design which will impact its mobility parameters. Radforth and Rush (1964) studied low ground pressure, now outdated, track only vehicles on Muskeg. Shoop (1995) presents equations for the minimum thickness needed for operating on frozen peat based on data from the late 1940's and early 1980's and does not tie it back to the soil strength parameters needed by current mobility codes. Additional work has been conducted by multiple individuals, but all studies are from the mid 1980's and earlier. The previously mentioned work either focuses on vehicle mobility on a single organic soil condition, or parameters generated from outdated vehicles. None of it includes vehicle traction or motion resistance on frozen or thawed organic soil. Vehicle technology and loading configurations have changed significantly in the past 35 years and mobility models need to be updated to better represent current military vehicles. This work presents preliminary mobility results of current military vehicles on highly organic terrain with the anticipation that some or all of the findings will eventually be implemented in existing mobility models to help better predict mobility on the highly organic soils found in northern regions.

\section{Field Testing}

\subsection{Testing Locations}

\section{i. Camp Ethan Allen Training Site (CEATS)}

Camp Ethan Allen Training Site is a Vermont National Guard site located in Jericho, VT which is home to the Army Mountain Warfare School and the $86^{\text {th }}$ Infantry Brigade Combat Team. CEATS has a wide range of terrains and soil types (Fig. 1a.) available for testing and it is in close proximity to CRREL making multi-season vehicle testing easier to conduct. Multiple potential sites were investigated before selecting the old air strip on the southern border of the training area (Fig. $1 \mathrm{~b}$ and Fig. 1d). This site was selected because of its ease of access, flat terrain, and organic soil composition (Fig. 1c).

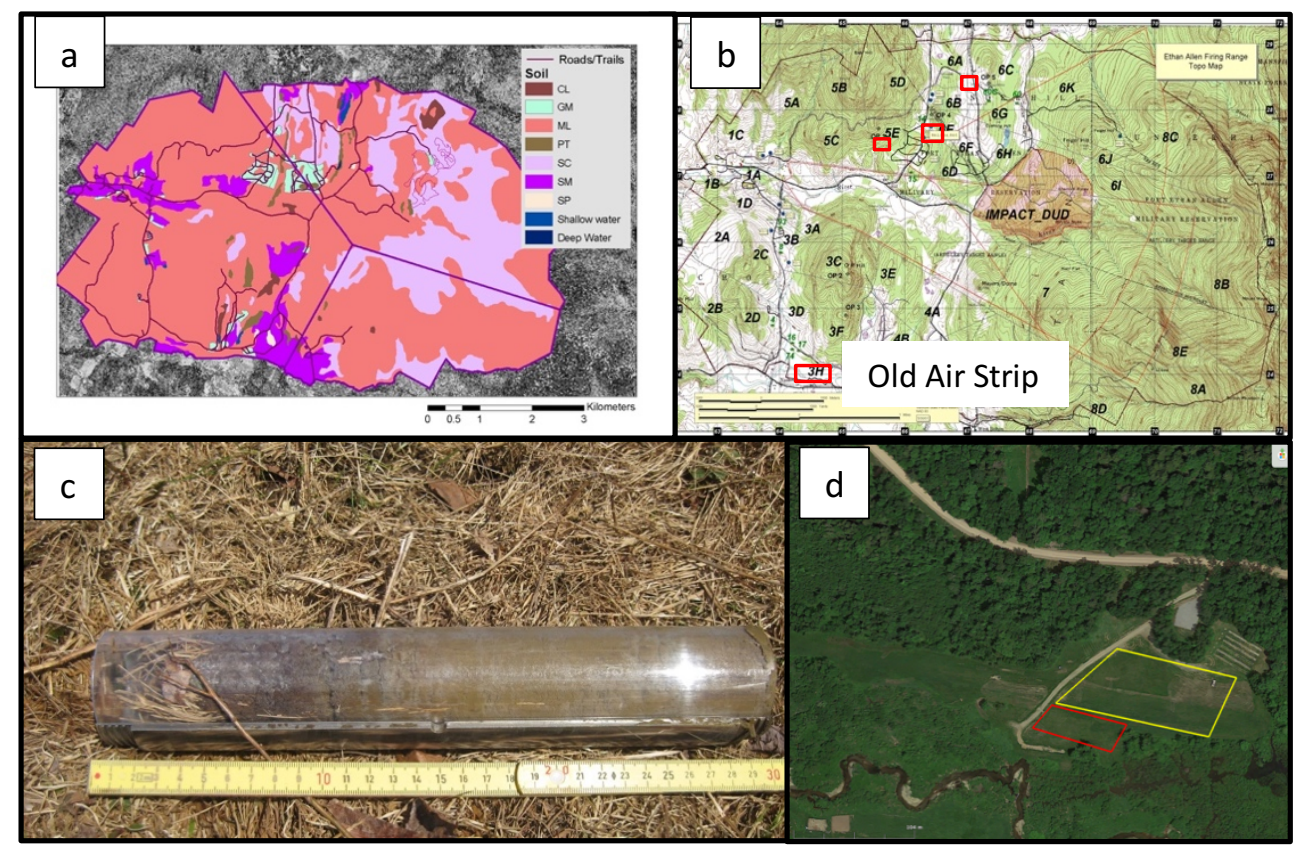

Fig. 1. a. Soils map for Camp Ethan Allen Training Site, $b$. Contour map showing candidate test locations, c. cross section of soil from split AMS tube sampler showing the organic layer which is typically 5-8 cm thick, d. Close-up of testing area. Test area (red), Practice area (yellow). 
Images of the test site at CEATS during winter and spring testing conditions can be seen in Fig. 2. The test area is flat and level, eliminating the need to conduct tests in both directions to eliminate slope effects.

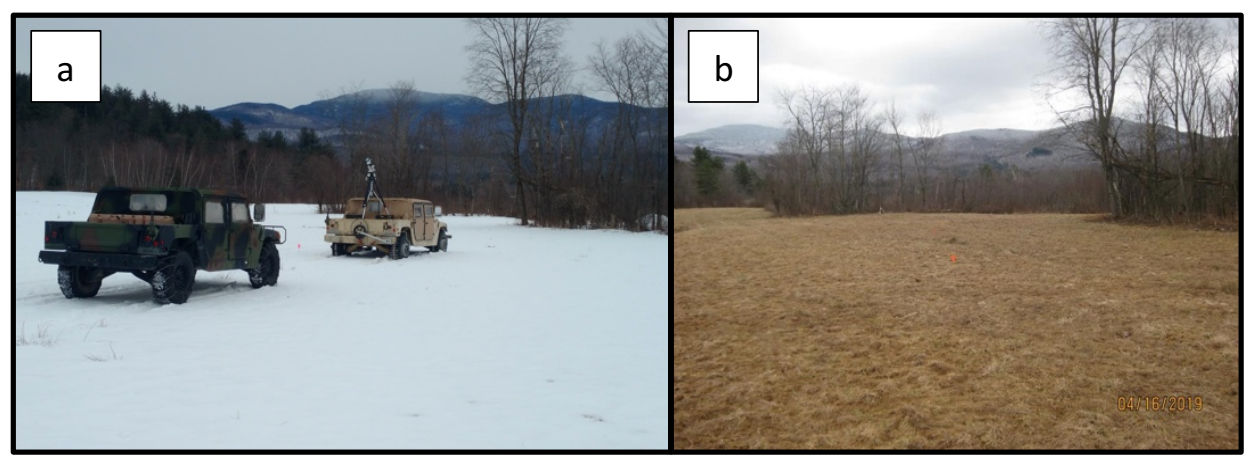

Fig. 2. a. Shallow snow winter test area (CEATS), February 2019, b. Spring wet condition (CEATS), April 2019.

CEATS has multiple types of wheeled and tracked vehicles on-site including High Mobility Multipurpose Wheeled Vehicles (HMMWVs) and Small Unit Support Vehicles (SUSVs) and organic soils making it a good test location.

\section{ii. Grantham Test Site}

The Grantham site is just south of CRREL in Grantham, NH and offers different types of vegetation, soil composition, and moisture content than CEATS. This site is also easily accessible by the test vehicles as it is bordered by the highway on one side and a state road on the other (Fig. 3).

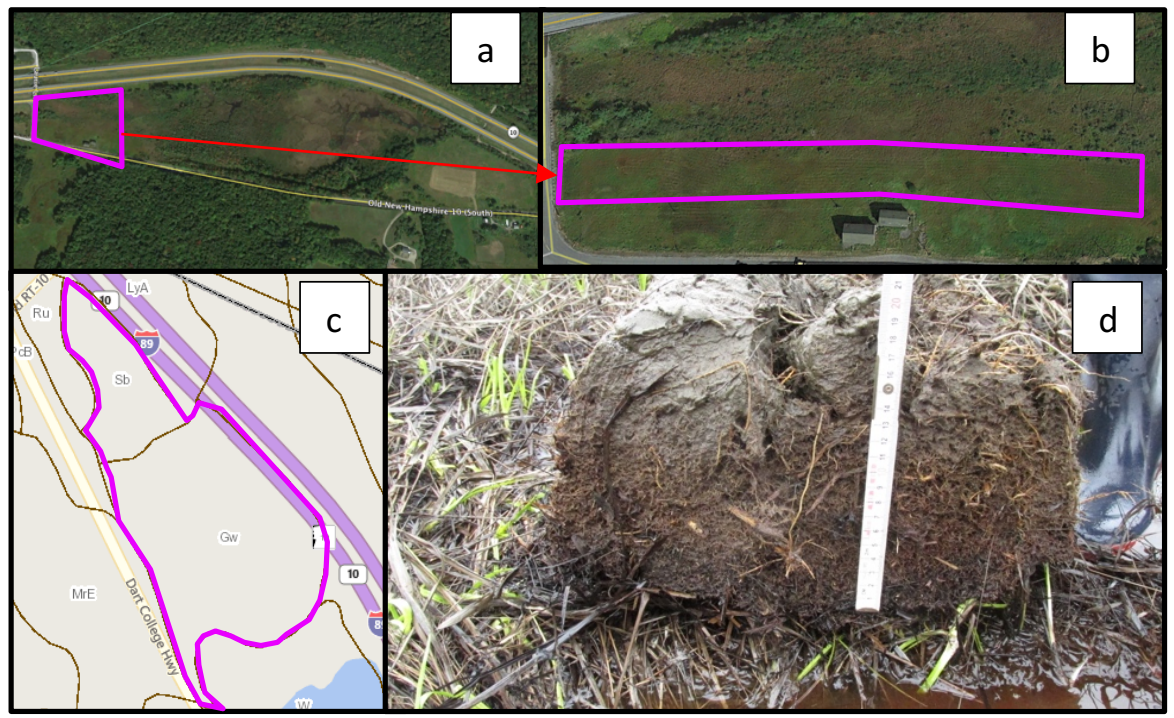

Fig. 3. a. Overview of Grantham test area, b. Close-up of vehicle test area, c. Soil types in test area. Sb-Saco mucky silty loam, Gw - Greenwood mucky peat, d. sample soil crosssection showing the organic layer which is typically $7-14 \mathrm{~cm}$ across the test site (soil plug is flipped upside down to highlight the organic content). 


\subsection{Test Vehicles and Instrumentation}

\section{i. $\quad$ Vehicles}

The same two vehicles, a 1097 HMMWV and a BV206 SUSV, were used for testing at CEATS and Grantham. These two vehicles were specifically chosen because they each have a low ground pressure allowing them to have the best chance of traversing the highly organic soil test sites during all test scenarios (winter, spring "wet", and summer "dry"). The HMMWV test vehicle is shown in (Fig. 4a.), and the BV206 SUSV is shown in (Fig. 4b.). Vehicle parameters are given in Table 1.

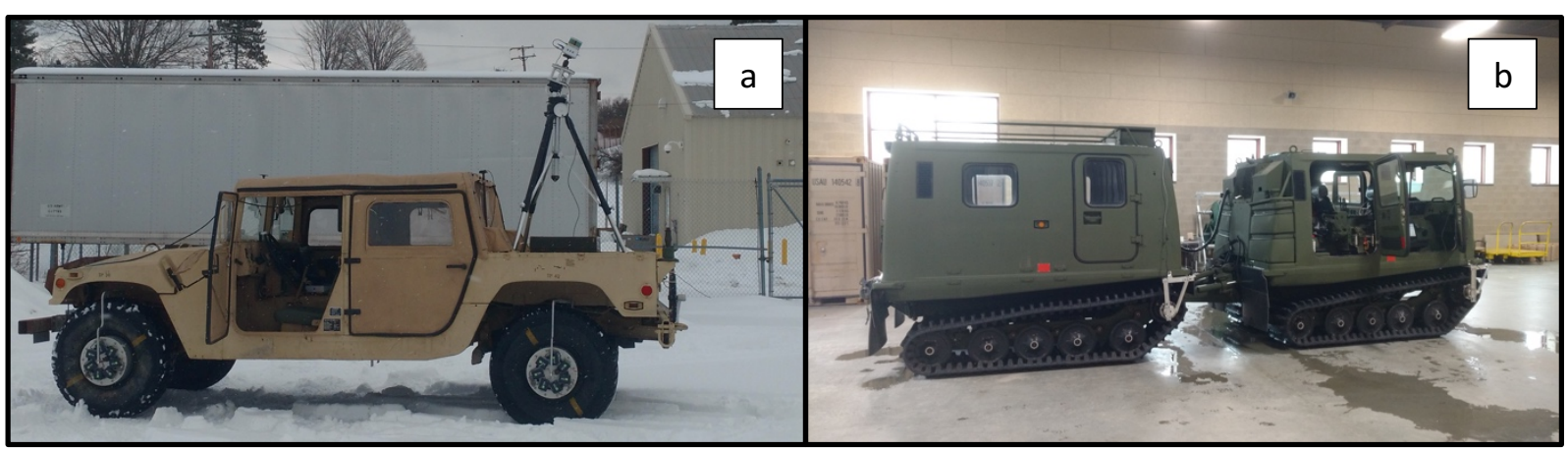

Fig. 4. a. 1097 HMMWV test vehicle fully instrumented with wheel load cells, LiDAR, vehicle speed, GPS, IMU, and wheel speed, $b$. SUSV test vehicle instrumented with LiDAR, vehicle speed, GPS, IMU, and track speed sensors.

Table 1. Vehicle parameters

\begin{tabular}{|c|c|c|}
\hline Parameter & HMMWV & SUSV \\
\hline Vehicle Weight $(\mathrm{kg})$ & 2994 & 6566 \\
\hline Center of Gravity Height $(\mathrm{cm})$ & 74.2 & 79.8 \\
\hline Ground Clearance $(\mathrm{cm})$ & 40.6 & 35.6 \\
\hline Vehicle Width $(\mathrm{cm})$ & 218.4 & 185.4 \\
\hline Vehicle Length $(\mathrm{cm})$ & 483.9 & 688.8 per unit \\
\hline Tire/Track Width $(\mathrm{cm})$ & 31.5 & 61.0 \\
\hline Tire Diameter/Track Length $(\mathrm{cm})$ & 93.0 & 198.1 \\
\hline Tread Width, Center-to-Center $(\mathrm{cm})$ & 181.9 & 125.0 \\
\hline Ground Surface Pressure $(\mathrm{kPa})$ & 83.4 & 13.3 \\
\hline
\end{tabular}

\section{ii. Vehicle Instrumentation}

Each vehicle was instrumented with a suite of sensors to help better understand its traction and mobility (Fig. 5). The instrumented HMMWV was equipped with individual wheel force transducers measuring lateral, longitudinal, and vertical forces and moments on each wheel (Sopher et al., 2016), an IMU measuring six degrees of freedom (surge, sway, heave, roll, pitch, yaw), a $5^{\text {th }}$ wheel mounted to the right rear of the vehicle to measure true vehicle speed, a GPS for position and vehicle speed, a LiDAR to measure wheel ruts, individual wheel speeds from an angular encoder, and a FLIR camera to measure ground surface parameters behind the vehicle. Driver input sensors including steering angle, throttle position, and brake pedal force were also installed in the HMMWV. The SUSV was instrumented with the same IMU measuring six degrees of freedom (surge, sway, heave, roll, pitch, yaw), GPS for position and vehicle speed, wheel speed sensors for wheel speed, LiDAR to measure track ruts, and a FLIR camera to measure terrain surface conditions behind the vehicle. Steering angle was measured using a string potentiometer to capture the articulation between the front and rear cabs of the SUSV. Gas pedal position was measured with a string potentiometer capturing $0-100 \%$ throttle, and brake pedal force was measured by a force transducer mounted to brake pedal. 


\section{iii. Soil Instrumentation and Measurements}

Multiple soil parameters were measured at each test site to characterize the test surface conditions during seasonal vehicle testing. Each site has a full meteorological station that continuously records air and soil conditions starting in November and continuing throughout the field test program. This allows for the monitoring and collection of seasonal organic soil conditions to see when/if the soil freezes/thaws and how the temperature and moisture changes with each season. The Met stations measure soil moisture, soil and air temperature, snow depth, liquid precipitation, wind speed and direction, relative humidity, air pressure, and incoming solar radiation. Localized soil samples and measurements were taken near each of the vehicle test areas to characterize the conditions. Soil characterization included measurements from the Troxler E-gauge (soil moisture and bulk density), Field Scout (volumetric moisture), Dynamic Cone Penetrometer (DCP, soil strength profile), Army cone penetrometer (soil strength), Clegg hammer (soil surface strength), split tube sampler (soil density, root structure, soil layering), and above and below ground vegetation classification (root size and density, vegetation types). Frankenstein et al. (2019) provide detailed soil testing procedures and data collected during the vehicle field testing covered in this report.

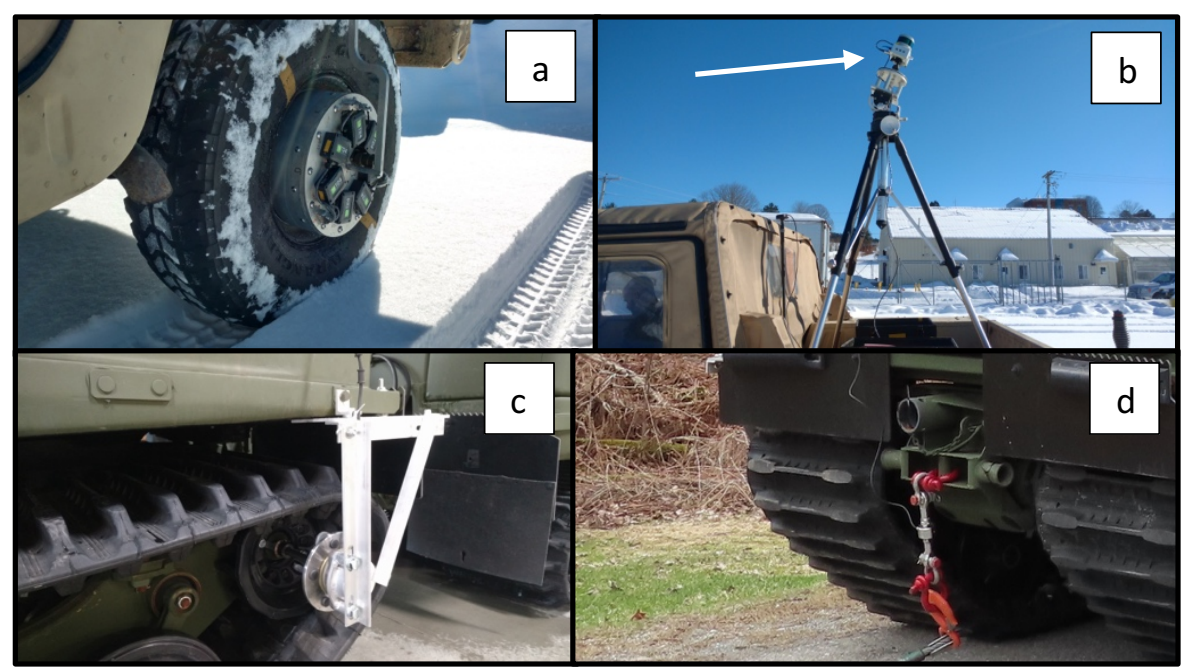

Fig. 5. a. Wheel Force Transducer (WFT) attached to the HMMWV, b. LIDAR on a tripod attached to the HMMWV measuring the ground profile behind the vehicle, $c$. wheel speed sensor on the SUSV measuring track speed. d. 50kN load cell attached to the SUSV measuring cable tension.

\section{Test Methods}

\subsection{Hard Surface Rolling Resistance (HSRR)}

Hard surface rolling resistance is designed to measure the internal and external rolling resistance of a test vehicle as it is pulled along a flat and level hard surface like asphalt. Internal vehicle rolling resistance typically consists of forces from items like the transmission, or transfer case, if they can't be fully disengaged, greased joints, and internal friction in bearings and track system. External rolling resistance is largely attributed to the interaction between the tire or track and the hard surface. HSRR should be measured by attaching the test vehicle to a tow vehicle with an inline cable and loadcell assembly and towing the test vehicle at a constant speed (typically $10 \mathrm{~km} / \mathrm{h}$ ) over a flat and level hard surface with the transmission in neutral.

\subsection{Motion Resistance}

Motion Resistance (MR) is a measure of how much force it takes to tow the test vehicle over a given surface condition. The test vehicle is attached to a tow vehicle with a cable and a load cell in an offset configuration so that the test vehicle is towed over an undisturbed test surface (Fig. 6). This is also done at a constant speed, typically $10 \mathrm{~km} / \mathrm{h}$. To get the 
true motion resistance caused by the terrain surface the HSRR is subtracted from the measured tow force. Equation 1 shows how motion resistance is calculated.

$$
M R_{\text {net }}=M R_{t s}-H S R R
$$

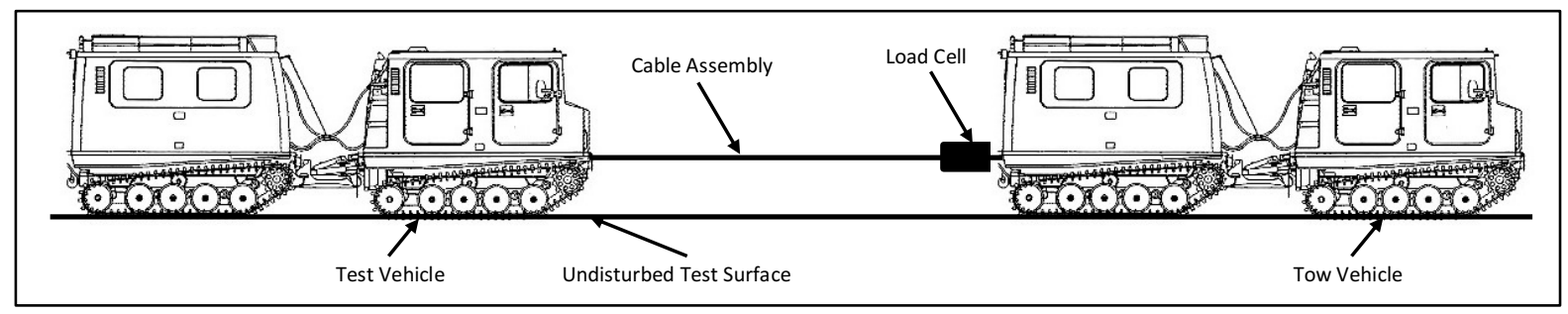

Fig. 6. Motion resistance schematic.

\subsection{Draw-Bar Pull}

Draw-bar pull (DBP) is the measured net tractive force the test vehicle can generate on a given surface condition. The test vehicle is connected in line to a hold back vehicle with a cable and load cell assembly (Fig. 7). The lead (test) vehicle slowly accelerates up to $10 \mathrm{~km} / \mathrm{h}$ on the flat and level test surface. Once at speed, the hold back vehicle applies the brakes while the test vehicle applies the throttle to maintain a constant speed (zero acceleration) of $10 \mathrm{~km} / \mathrm{h}$, causing the test vehicle to lose traction allowing tracks or wheels to slip or spin. During the DBP it is difficult to limit intermittent acceleration. In post-processing the additional load caused by any intermittent acceleration must be accounted for to get true tractive force values. The equation for draw-bar pull is:

$$
T f_{n e t}=m a_{t v}+F_{c}
$$

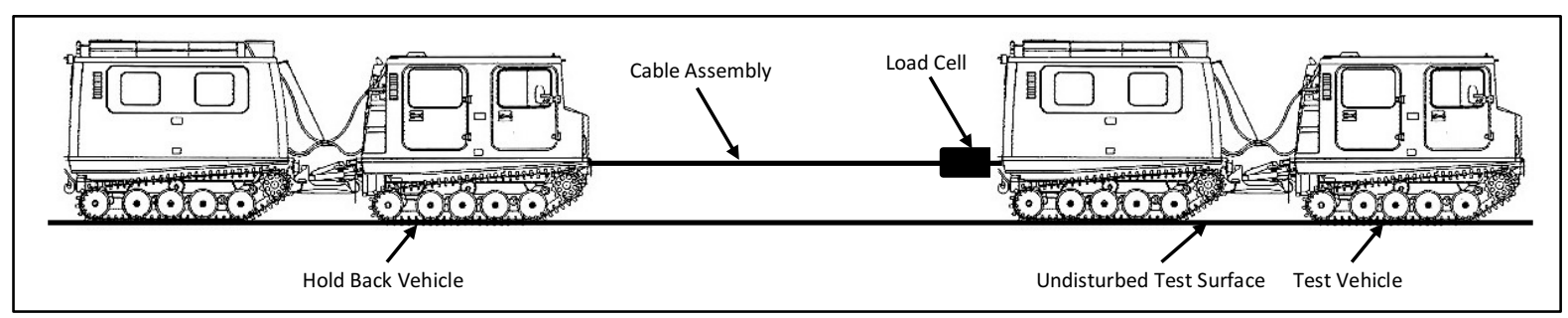

Fig. 7. Draw-bar pull schematic.

\section{Experimental Results}

Experimental vehicle testing focused on collecting mobility data for a light wheeled and a light tracked vehicle driving over highly organic terrain. Testing was conducted over multiple terrain conditions including shallow snow over frozen organic soil (winter) and wet organic soil conditions (spring). Testing will be conducted on "dry" organic soil conditions and are scheduled to be completed during the 2019 summer. From these, vehicle traction results for three of the four typical seasons will be produced. The only missing season is bare frozen soil. So far vehicle field testing has been conducted during winter and spring at CEATS, and spring only at Grantham. The terrain conditions for the three tests are summarized below.

- During February testing at CEATS, the test site consisted of snow over frozen organic soil and vegetation. The snow had an average depth of $11.9 \mathrm{~cm}$ with a density of $0.318 \mathrm{~g} / \mathrm{cm}^{3}$.

- The April test at CEATS had no snow and the vegetation was still dormant since the previous fall. The soil was firm with neither test vehicle leaving ruts during motion resistance or the DBP testing.

- The June tests at Grantham was characterized as wet with some areas of shallow standing surface water. The soil was soft enough in spots, mostly where there was standing surface water, for the vehicles to leave significant ruts behind. 


\subsection{Hard Surface Rolling Resistance (HSRR)}

HSRR tests at the CEATS and Grantham test sites were conducted on a flat asphalt surface with a target speed of $10 \mathrm{~km} / \mathrm{h}$. The tests for each vehicle were conducted the same day that draw-bar pull and motion resistance were measured to minimize the effects of temperature on HSRR. HSRR results for the HMMWV and the SUSV at both sites are shown in Fig. 8. Since both tests were recorded on flat and level asphalt the only difference between the values for a given vehicle is the temperature at which the test was performed. Both vehicles show that temperature can have a significant impact on this measurement and why it is important to repeat this measurement at the same temperature at the other tests. This effect is largely caused by greases and oils becoming stiffer or more viscous at low temperatures.

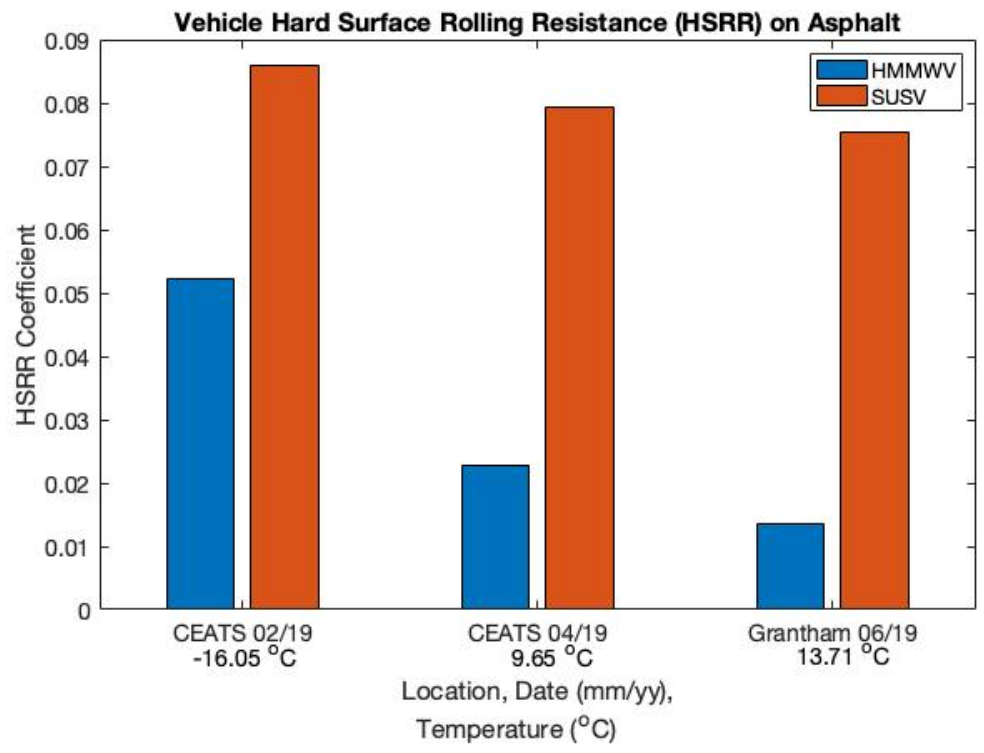

Fig. 8. Hard surface rolling resistance for HMMWV and SUSV at CEATS and Grantham test sites.

\subsection{Motion Resistance (MR)}

Motion resistance values for the HMMWV and SUSV were measured at each of the test sites. MR for the HMMWV during the February CEATS test was conducted using a second 1097 HMMWV to offset tow the CRREL instrumented 1097 HMMWV. The April and June HMMWV MR tests were conducted using a SUSV to offset tow the CRREL HMMVW. The different configurations were selected to minimize soil disturbance resulting from the tow vehicle. During the February SUSV MR testing at CEATS, a 1085 Wrecker was used tow the SUSV. The Wrecker's cable was spooled out to allow it to connect to the SUSV while remaining off the test section so that it did not disturb the snow prior to the SUSV MR test. Once connected, the Wrecker pulled the SUSV across the test area at a constant speed of $10 \mathrm{~km} / \mathrm{h}$. This was not necessary for the April tests because the SUSV did not disturb the ground. For the Grantham testing, a special tow bar was developed and built by CRREL to attach to the lead SUSV allowing it to tow the instrumented SUSV in an offset configuration.

Figure 9 shows the results from the MR testing at both test locations. The HMMWV has significantly higher MR than the SUSV because it has a much higher ground pressure of $83.4 \mathrm{kPa}$ versus $13.3 \mathrm{kPa}$ for the SUSV. This higher ground pressure causes it to have a larger sinkage than the SUSV when traversing over the same terrain, which directly increases the motion resistance. In general, the HMMWV and SUSV experience the same general overall trends in MR when comparing the three tests. Results from the February tests show that the shallow snow layer in the winter increases MR because each vehicle sinks into the snow. When comparing the April and June tests, the MR is higher in June because both vehicles had notable sinkage into the much softer soil. During April testing, the soil was noticeably drier and firmer and neither vehicle had any measurable sinkage. The two different bars (red and yellow) for the SUSV in June show the MR for the north and south sides of the test site in Grantham (Fig. 3b: north is left of the barns in the image). The north side was much wetter, slightly lower, and contained more standing water which increased the MR for the vehicle. There are no results for the HMMWV on this side because it was deemed too soft. 


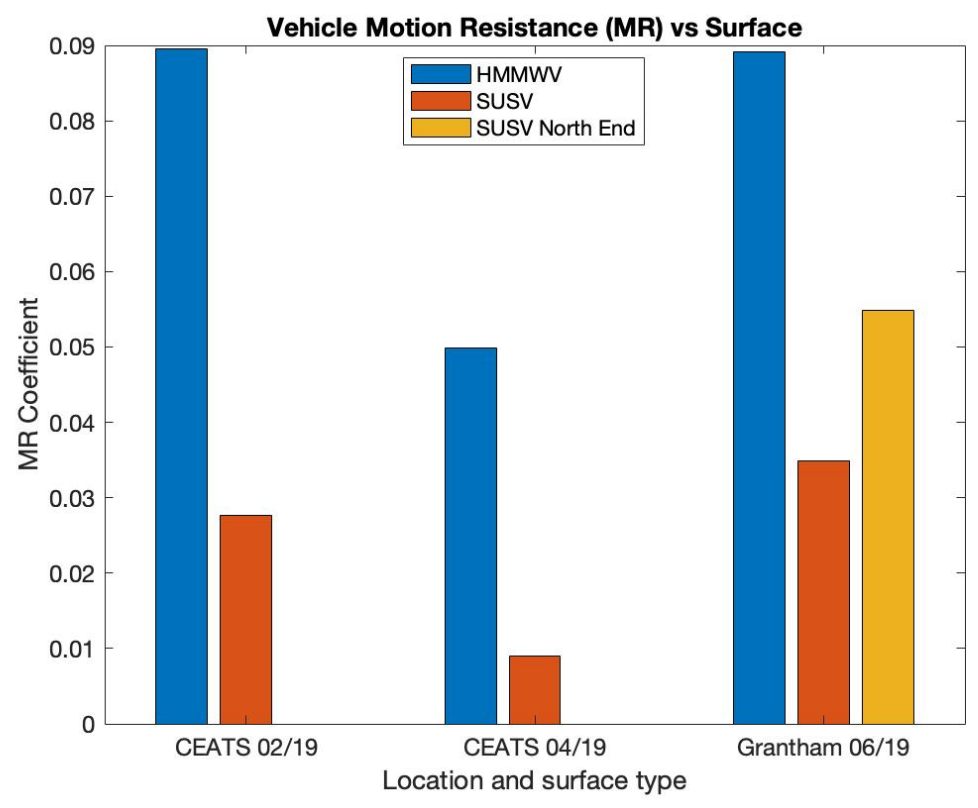

Fig 9. Motion resistance for HMMWV and SUSV at CEATS and Grantham test sites.

\subsection{Draw-Bar Pull (DBP)}

Draw-bar pull values for the HMMWV and SUSV were measured at each of the test sites: during February and April at CEATS and during June at Grantham. For the February testing at CEATS there was an average of $11.9 \mathrm{~cm}$ of snow over frozen ground, the DBP tests for the HMMWV were conducted using the instrumented HMMWV (no tire chains) to inline tow a second 1097 HMMWV. The second HMMWV was used as the hold back vehicle and was outfitted with tire chains and $190 \mathrm{~kg}$ of additional weight to increase traction. During each test, the instrumented HMMWV dug down through the snow and spun up some of the vegetation (from the frozen organic soil) onto the surface of the snow. This confirmed that it was interacting with the frozen soil and represented a good snow and frozen organic soil test and not just a snow DBP test. SUSV DBP tests were conducted by towing a holdback SUSV, with $190 \mathrm{~kg}$ of additional weight, with the instrumented SUSV. The ruts left behind after each test indicated that the SUSV also dug down through the snow to the ground surface and spun up vegetation onto the snow indicating a good snow and frozen soil DBP test.

During the April testing at CEATS there was no snow and the ground was completely thawed. The HMMWV DBP tests were conducted using the instrumented HMMWV (no tire chains) to inline tow a second 1097 HMMWV. The second HMMWV behaved as the hold back vehicle and was outfitted with tire chains, but no water cans. For each test, there did not appear to be any significant sinkage into the soil but there was vegetation removal due to the spinning of the tires. For the SUSV DBP tests, the instrumented SUSV inline towed the hold back SUSV and a 1097 HMMWV with chains. Practice runs were conducted prior to the first SUSV DBP test with just a single SUSV as a hold back vehicle to determine if that configuration would be enough to conduct a successful DBP. The second SUSV was dragged when full brakes were applied so a 1097 HMMWV with chains was added inline behind the holdback SUSV. An additional practice test indicated that this configuration was enough to hold back the instrumented SUSV. After visual inspection of the ruts, there was indication that the instrumented SUSV spun up grass, similar to the HMMWV, but did not dig up any soil.

June testing took place on heavily vegetated and wet soil in Grantham. DBP tests for the HMMWV were conducted using the instrumented HMMWV (no tire chains) to inline tow a SUSV as the hold back vehicle. This was necessary because of the soft ground conditions. All other vehicles onsite would have either gotten stuck or not been able to hold back the HMMWV. The instrumented HMMWV completed three good DBP test over the length of the test section, but the conditions varied from one end to the other ranging from no standing water, shallow standing water and deep standing water. As expected, this caused the DBP values to decrease as the moisture level increased as indicated in Fig. 10a. The June SUSV DBP tests were conducted by having the instrumented SUSV inline tow the hold back SUSV. Initial tests were conducted with the hold back SUSV unweighted. This resulted in test vehicle dragging the holdback vehicle so we added 360-450 kg of weight evenly across the front and rear car of the holdback SUSV to increase its hold back capability. 
The additional weight sufficiently increased the holdback force and multiple DBP tests were conducted. In each of these tests the instrumented SUSV's tracks spun, ripping off some of the vegetation tops, but they did not dig down to the soil surface. The June SUSV DBP tests were conducted on both the north and south side of the Grantham test section (both sides of the barn in Fig. $3 \mathrm{~b}$ ) to see how the higher water table (standing water) and more grass like vegetation would affect the end results.

Figure 10b shows the DBP results for all tests at both sites. The higher water table and more grass like vegetation had very little effect on the DBP value as both test results were nearly identical. Figure 10b also shows a 75-100 percent increase in traction for the SUSV when operating on the non-snow covered and unfrozen organic soil conditions. The HMMWV had greater than a 100 percent improvement in traction between the winter and spring CEATS test, but experienced similar traction values between winter CEATS and spring Grantham tests. This is because the HMMWV had high sinkage values in Grantham and spun down through the vegetation and into the wet organic soil.
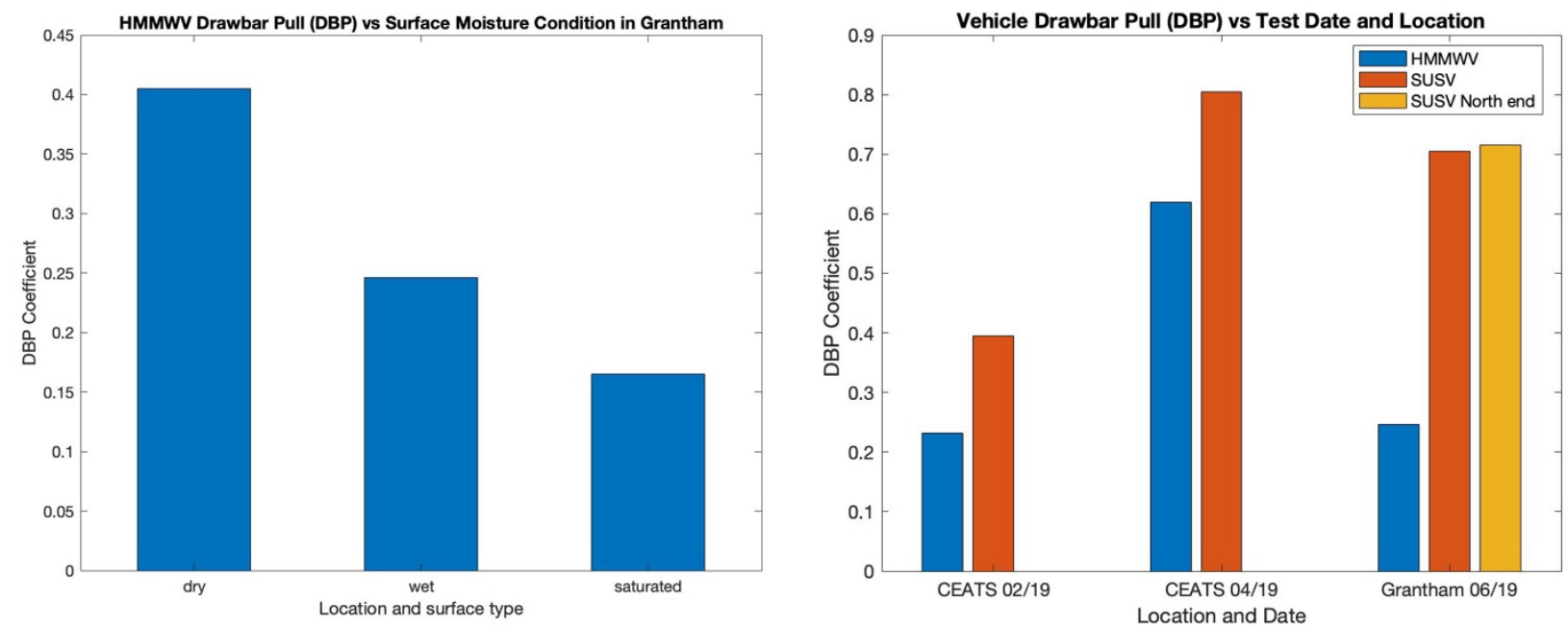

Fig 10. a. HMMWV Draw-bar Pull variation across the Grantham test site. $b$. Draw-bar Pull for HMMWV and SUSV at CEATS and Grantham test sites.

\section{Conclusions}

The HMMWV and SUSV were used for vehicle mobility testing on two separate highly organic soil test sites in New England. Preliminary analysis of the results from this testing show the mobility of the light wheeled and light tracked vehicles on these two highly organic, but different test conditions. Soft snow and wet soil conditions provide the highest motion resistance for both vehicles due to track/wheel sinkage into the terrain or standing water on the test area. The higher ground pressure of the HMMWV caused it to have a higher sinkage into the snow and soft soil reducing the net traction. Highly organic soils have a wide variability of soil and vegetation conditions which greatly affect vehicle sinkage and traction. This affect is less apparent on the low ground pressure tracked vehicle because the tracks smooth out the uneven terrain and allow for better flotation. Future work will include testing with additional vehicle conditions, and meteorology to better describe the site vegetation and variability.

\section{Nomenclature}

$a_{\mathrm{tv}}$

CEATS

CRREL

DBP

DCP

$\mathrm{F}_{\mathrm{c}}$

FLIR
Longitudinal acceleration of test vehicle

Camp Ethan Allen Training Site

Cold Regions Research and Engineering Laboratory

Draw-bar Pull

Dynamic Cone Penetrometer

Hold back force on the cable

Forward Looking InfraRed $\left(\mathrm{m}^{\wedge} 2 / \mathrm{s}^{\wedge} 2\right)$ 


$\begin{array}{lll}\text { GPS } & \text { Global Positioning System } & \\ \text { Gw } & \text { Greenwood mucky peat } & \\ \text { HMMWV } & \text { High Mobility Multipurpose Wheeled Vehicle } & \\ \text { HSRR } & \text { Hard Surface Rolling Resistance } & (\mathrm{N}) \\ \text { IMU } & \text { Inertial Measurement Unit } & \\ \text { LiDAR } & \text { Light Detection and Ranging } & \\ \text { m } & \text { mass of the test vehicle } & (\mathrm{kg}) \\ \text { MET } & \text { Meteorological } & \\ \text { MR } & \text { Motion Resistance } & (\mathrm{N}) \\ \text { MR }_{\text {net }} & \text { Net test surface motion resistance } & (\mathrm{N}) \\ \text { MR }_{\text {ts }} & \text { Towed test surface motion resistance } & (\mathrm{N}) \\ \text { SUSV } & \text { Small Utility Support Vehicle } & \\ \text { Sb } & \text { Saco mucky silty loam } & \\ \mathrm{Tf}_{\text {net }} & \text { Net tractive force } & (\mathrm{N})\end{array}$

\section{Acknowledgements}

The authors would like to acknowledge the assistance of Bruce Elder, Lynette Barna, Jason Olivier, Michelle Michaels, Michele Maxson, and Brian Quinn for their assistance in collecting field data, and to Lynette Barna for reviewing this paper. Funding for this effort was provided by the Mobility in Peat and Northern Soils project under the 6.2 T40 ASTMIS Task \#48: Entry and Sustainment in Complex Contested Environments work package.

\section{References}

Frankenstein, S., Barna, L.A., Elder, B.C., Shoop, S.A., Michaels, M.L., Feyrer, M.C., 2019. Peat and Organic Soil Characterization during Seasonal Mobility Testing. $15^{\text {th }}$ ISTVS European-African Regional Conference.

Radforth, N.W., Rush, E.S., 1964. Trafficability tests on confined organic terrain (muskeg). WES TR 3-656.

Shoop, S.A., 1995. Vehicle bearing capacity of frozen ground over a soft substrate. J. Can. Geotech. 32, 552-556.

Shoop, S.A., Coutermarsh, B.A., Cary, T.J., Howard, H.R., 2015. Quantifying vegetation biomass impacts on vehicle mobility. J. Terramechanics. 61 63-76.

Sopher, A.M., Shoop, S.A., Stanley, J.M., Els, S., Becker, C., Botha, T., 2016. Instrumentation and testing of a high mobility multipurpose wheeled vehicle. $8^{\text {th }}$ ISTVS Americas Regional Conference.

Wong, J.Y., Garber, M., Preston-Thomas, J., 1984. Theoretical prediction and experimental substantiation of ground pressure distribution and tractive performance of tracked vehicles. IMechE .198D No 15, 265-285. 


\section{REPORT DOCUMENTATION PAGE}

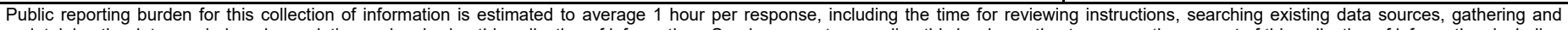

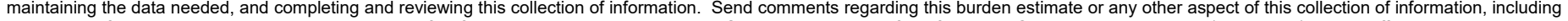

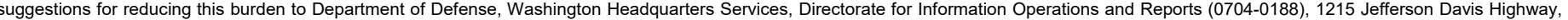

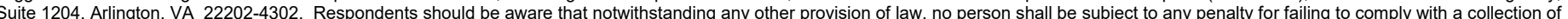
information if it does not display a currently valid OMB control number. PLEASE DO NOT RETURN YOUR FORM TO THE ABOVE ADDRESS.

\section{\begin{tabular}{l|l|l} 
information if it does not display a currently valid OMB control number. PLEASE DO NOT RETURN YOUR FORM TO THE ABOVE ADDRESS. \\
\hline 1. REPORT DATE & 2. REPORT TYPE
\end{tabular}}

\begin{tabular}{l|l|l}
\hline $\begin{array}{l}\text { 1. REPORT DATE } \\
\text { August } 2020\end{array}$ & $\begin{array}{c}\text { 2. REPORT TYPE } \\
\text { Final }\end{array}$ & 3. DATES COVERED (FrOm - To)
\end{tabular}

\section{TITLE AND SUBTITLE}

Vehicle Mobility on Highly Organic Soils

5a. CONTRACT NUMBER

\section{AUTHOR(S)}

Michael Parker, Alexander Stott, Mark Bodie, Susan Frankenstein, and Sally Shoop

\section{5b. GRANT NUMBER}

5c. PROGRAM ELEMENT NUMBER 62784

5d. PROJECT NUMBER

AT40

5e. TASK NUMBER

48

5f. WORK UNIT NUMBER

7. PERFORMING ORGANIZATION NAME(S) AND ADDRESS(ES)

U.S. Army Engineer Research and Development Center

Cold Regions Research Laboratory

8. PERFORMING ORGANIZATION REPORT NUMBER

72 Lyme Road

Hanover, NH 03755

\section{SPONSORING / MONITORING AGENCY NAME(S) AND ADDRESS(ES)}

Assistant Secretary of the Army/Acquisitions, Logistics \& Technology

103 Pentagon

Washington, DC 20314-1000

ERDC/CRREL MP-20-8

\section{DISTRIBUTION / AVAILABILITY STATEMENT}

Approved for public release; distribution is unlimited.

\section{SUPPLEMENTARY NOTES}

Originally published in Proceedings of the ISTVS 15th European-African Regional Conference, Prague, Czech Republic, September 9-11, 2019

\section{ABSTRACT}

Current political climates have generated a renewed interest in the northern regions of the world. These areas are known to have soft marshy peat, highly organic soils, and cold harsh winter climates. Currently vehicle mobility modeling capability on this terrain is limited and existing studies do not include current military vehicles. This work presents mobility experiments of current military vehicles at multiple field sites containing peat or highly organic soils that can eventually be used to improve mobility modeling on these soils. Field work is being conducted during multiple seasons including winter, spring, and summer. The vehicle traction, motion resistance, and hard surface rolling resistance of an instrumented High Mobility Multipurpose Wheeled Vehicle (HMMWV) and a Small Unit Support Vehicle (SUSV) were examined. The first is a common multi-purpose vehicle and the second is a vehicle designed to operate in these types of environments. Preliminary analysis of the field test results will be discussed in this paper.

\section{SUBJECT TERMS}

Peat, Organic, Soil, Vehicle Mobility, Tracked Vehicle

\section{SECURITY CLASSIFICATION OF:}

\begin{tabular}{l|r}
\hline a. REPORT & b. ABSTRACT \\
Unclassified & Unclassified
\end{tabular}

17. LIMITATION OF ABSTRACT

c. THIS PAGE

Unclassified 18. NUMBER
OF PAGES

SAR
13 19a. NAME OF RESPONSIBLE PERSON

19b. TELEPHONE NUMBER (include area code) 